Trans

continentales

\title{
Transcontinentales
}

Sociétés, idéologies, système mondial

\section{Le mécène, un acteur méconnu de la ville}

Istanbul à l'heure des musées privés

The Patron, a Little-Known Urban Actor. Istanbul with the Advent of Private

Museums

Nora Seni

\section{OpenEdition}

\section{Journals}

Édition électronique

URL : http://journals.openedition.org/transcontinentales/374

DOI : 10.4000/transcontinentales.374

ISBN : 978-2-7351-1559-4

ISSN : 1775-397X

Éditeur

Editions de la maison des sciences de l'homme

\section{Édition imprimée}

Date de publication : 30 juin 2009

Pagination : 105-128

ISBN : 978-2-200-92512-3

ISSN : 1950-1684

\section{Référence électronique}

Nora Seni, «Le mécène, un acteur méconnu de la ville », Transcontinentales [En ligne], 7 | 2009,

document 6 , mis en ligne le 30 mars 2011, consulté le 07 septembre 2020. URL : http://

journals.openedition.org/transcontinentales/374 ; DOI : https://doi.org/10.4000/transcontinentales. 374 


\title{
Le mécène, un acteur méconnu de la ville
}

\author{
Istanbul à I’heure des musées privés
}

\author{
Nora Seni
}

Depuis que l'équipement culturel s'est imposé comme un instrument majeur de la valorisation territoriale, le musée est devenu le motif central d'un nouveau paradigme de l'action urbaine. Ce paradigme implique également un projet urbain, un architecte de renom, un amateur d'art qui fait donation de sa collection. Parallèlement une littérature a fleuri ${ }^{1}$, en France et dans le monde, qui analyse l'impact des entreprises culturelles et artistiques pérennes - musées privés ou publics -, éphémères ou cycliques - festivals, biennales, tout un ensemble d'événements qui se transforment en "rituels urbains ${ }^{2}$ ». Il est remarquable qu'en France les recherches privilégient l'approche par les politiques publiques et n'ajustent que très rarement leur focale sur les initiatives privées ${ }^{3}$. Ainsi, les analyses se consacrent au repérage des stratégies d'acteurs quasiment tous publics. Or, des initiatives sont prises, comme la création de musées ou l'organisation de festivals par des acteurs privés ou du moins par des fondations à but non lucratif.

1 - Voir F. Bianchini et M. Parkinson (éd.), Cultural, Policy and Urban Regeneration : the West European Experience, Manchester, Manchester University Press, 1993; F. Lucchini, La culture au service des villes, Paris, Anthropos, 2002; H. Mommaas, "Cultural clusters and the post-industrial city : towards the remapping of urban cultural policy», Urban Studies, 2004(3), p. 507-532; M. Miles, Cities and Cultures, Londres, Routledge (Critical Introductions to Urbanism and the City), 2007; G. Saez (dir.), Institutions et vie culturelles, Paris, La Documentation française, 2005; P. Tronquoy (dir.), Les Cahiers Français, n 312 "Culture, État et marché», janvier-février 2003; S. Zukin, The Cultures of Cities, Cambridge-Oxford, Blackwell Publisher, 1995.

2 - C. Landry, The Art of City-Making, Londres, Earthscan, 2006, p. 176.

3 - E. Négrier, L. Michel et D. Yaouanc (dir.), Une politique culturelle privée en France? Les nouveaux commanditaires de la Fondation de France, Paris, L'Harmattan, 2006; J.-M. Tobelem, Musées et culture, le financement à l'américaine, Mâcon, Éditions W, 1990 ; id. (dir.), La culture mise à prix : la tarification dans les sites culturels, Paris, L'Harmattan, 2005; id., Le nouvel âge des musées: les institutions culturelles au défi de la gestion, Paris, Armand Colin, 2005. 
Si le cadre conceptuel et analytique dans lequel il est d'usage d'inscrire les questions territoriales permet bien d'aborder l'installation d'une antenne du musée du Louvre dans la ville de Lens (projet Louvre-Lens) ou du Centre Pompidou à Metz, il ne permet guère de rendre compte des logiques qui président, par exemple, à la création et au fonctionnement de la Maison rouge-Fondation Antoine de Galbert près de la Bastille à Paris, ou à l'aventure - solitaire et sans partenariat privé/public prévu - d'un Marcel Brient, autodidacte qui cherche à fonder à Montreuil l'Espace Louis-Clayeux pour y exposer sa collection d'art contemporain et espère, à terme, transformer l'ensemble en musée municipal ${ }^{4}$.

Ainsi, ne sont guère élaborées des démarches spécifiques, des instruments analytiques pour rendre compte des logiques de ces hommes d'affaires, collectionneurs, donateurs, créateurs de fondations artistiques ou de musées. Il est pourtant important de les identifier comme un type d'acteur émergent, d'en établir l'archétype et de le situer dans la durée historique pour cerner les mutations de son rôle social. Les visées de ce personnage ne sont pas forcément d'ordre territorial, ni d'ailleurs exclusivement artistiques ou culturelles, mais elles induisent des incidences fortes sur l'espace urbain. Ce donateur apparaît-il seulement aujourd'hui? Si oui pourquoi maintenant? S'agit-il de la résurgence de la figure de la fin du xIX $^{\mathrm{e}}$ siècle du notable philanthrope et mécène qui, à l'instar de Moïse de Camondo (1821-1896), Henri Cernuschi (1821-1896) ou des Jacquemart-André, collectionnait objets d'art et peintures, les installait dans sa demeure conçue à cet effet, et léguait l'ensemble à l'État pour qu'il en fasse un musée ${ }^{5}$ ? Comment aborder l'établissement et la diffusion de cette conduite - collectionner/donner - en marqueur social qui s'impose comme une contrainte à un milieu, à une certaine strate sociale? Que dire aujourd'hui de cette figure majeure de l'interface arts/territoires ou culture/ville, et cela même dans un pays comme la France où

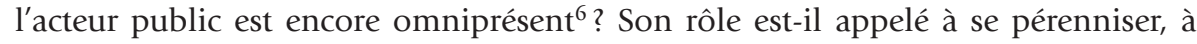
être conforté sur la scène culturelle des métropoles et de leur concurrence? Ce rôle est-il voué à infléchir fortement les logiques urbaines? Ces interrogations s'inscrivent sur un arrière-plan de privatisation relative des politiques culturelles. La question qui se pose est aussi la suivante: dans des contextes où les initiatives culturelles et artistiques des fondations et mécènes sont importantes, comment se définit l'intérêt général et qui le définit?

4 - Louis Gabriel Clayeux «fut l'œil du marchand Aimé Maeght»; c'est lui qui initia Marcel Brient à l'art contemporain. Marcel Brient siégea trois ans à la commission d'acquisition de Beaubourg (voir Nathaniel Herzberg, "Marcel Brient, la collection d'une vie suspendue aux lenteurs de la justice», Le Monde, 3 juin 2007).

5 - Voir Les donateurs du Louvre, Paris, Réunion des musées nationaux, 1989; Véronique Long, Mécènes des deux mondes. Les collectionneurs donateurs du Louvre et de l'Art Institute de Chicago, 18791940, Rennes, Presses universitaires de Rennes, 2007.

6 - S'exprimant dans les colonnes du journal Le Monde du 14 février 2008 Jacques Rigaud, qui a présidé durant vingt-huit ans l'Admical, association chargée de promouvoir le mécénat auprès des entreprises, précise: "Que représentait le mécénat dans les années 1970? Il se limitait aux actions de quelques grandes fortunes: Suzanne Tézenas, les David-Weil, ou les Boissonnas. Il devenait urgent de développer un mécénat d'entreprise. Mais c'était très mal vu.» 
Ce n'est pas parce que François Pinault a renoncé à installer sa collection au cœur de l'île Seguin qu'il n'est plus nécessaire d'analyser l'instrumentalisation de sa donation dans le cadre d'initiatives territoriales, maintenant la requalification des anciennes douanes de mer à Venise. Il faudra bien que l'on s'intéresse aussi à la Fondation Louis-Vuitton pour la création que Bernard Arnault fait construire à Frank Gehry, au bord du jardin d'Acclimatation de Paris. La Donation Albers-Honegger est aussi une collection privée - d'art concret - logée dans un milieu naturel ${ }^{7}$, le parc du château de Mouans-Sartoux (Alpes-Maritimes) où un espace a été inauguré en 2004 pour exposer les œuvres issues de la collection Sybil Albers et Gottfried Honegger. Il faut désormais intégrer cette réalité : en France aussi - pas seulement aux États-Unis et dans les Émirats arabes unis - des particuliers créent musées et centres culturels, fondent des lieux d'exposition non marchands et participent à la définition de l'intérêt collectif, induisant de nouvelles orientations dans les politiques culturelles et territoriales. S'il faut analyser ce que l'on peut appeler provisoirement une privatisation relative, partielle, des politiques culturelles et territoriales, il est important de connaître l'identité des acteurs qui portent cette tendance.

Cet article a pour ambition de proposer une réflexion sur un de ces acteurs en termes d'idéal-type : l'homme d'affaires-collectionneur-donateur-créateur de musée. Il se propose de repérer les logiques qui le guident, d'analyser les impacts de ses actions. Pour mener cette réflexion les rives de la Seine seront abandonnées ainsi que la France, au profit de la ville d'Istanbul. En effet, cette métropole se distingue par une vitalité surprenante dans le domaine des événements culturels internationaux ${ }^{8}$ menés à l'initiative d'un secteur "à but non lucratif» en pleine croissance et par un nombre considérable de musées privés fondés dans les dix dernières années. En Turquie, le ministère de la Culture a gardé le monopole de l'action jusqu'aux années 1980. Vasif Kortun, conservateur en chef de la IXe Biennale d'Istanbul, distingué en 2005 pour sa réussite parmi cent personnages choisis par la revue new-yorkaise Art + Auction, affirmait que «l'État turc n'a plus de relations avec l'art (sa production, son exposition) depuis plus de vingt-cinq ans et que la vitalité de l'univers artistique à Istanbul est exclusivement due aux indépendants ${ }^{9}$ ». Depuis ce retrait de l'État, fondations privées, grandes familles émergentes ont ensemble transformé le paysage artistique et culturel, sinon du pays, du moins de la ville d'Istanbul. Leur dynamisme n'est sans doute pas étranger à l'élection de cette ville comme «Capitale européenne de la culture» en $2010^{10}$. On peut au passage

7 - Voir http://www.crdp.ac-nice.fr/eac/menu_donation.htm.

8 - S. Yardimci, Kentsel degisim ve Festivalizm. Küresellesen Istanbul'da Bienal [Transformation urbaine et festivalisme: la Biennale dans Istanbul globalisée], Istanbul, Iletisim, 2005.

9 - Interview avec Vasif Kortun dans l'hebdomadaire Salom du 5 avril 2006. Dans cet entretien Vasif Kortun qualifie les établissements artistiques de dernier carré d'espace public (Sanat kurumlari son kamusal alanimiz)

10 - Sept villes françaises se disputent le titre pour 2013: Lyon, Marseille, Bordeaux, Nice, Saint-Etienne, Strasbourg, Toulouse. Ce titre est l'occasion pour les villes de changer d'image, d'obtenir une reconnaissance internationale. En 2004, 700000 personnes ont rendu visite à Lille, et trois ans plus tard, François Pinault y exposait pour la première fois en France une partie de ses collections. Sur l'intérêt, pour une ville, d'être élue capitale européenne de la culture, voir aussi M. Miles, Cities and Cultures..., op. cit. 
se souvenir qu'en 1836 un certain Charles Fourrier voyait en Constantinople «la capitale du monde», le "siège central de son gouvernement unitaire ${ }^{11}$. Mais ceci est une tout autre histoire qui appartient à l'époque où la capitale ottomane représentait pour l'imaginaire occidental un objet insaisissable et fascinant.

Aujourd'hui, Istanbul est une ville tangible qui suscite moins de projections utopiques ou romanesques. Un élément supplémentaire fait de cette cité un cas exemplaire pour la question qui nous occupe: avant de devenir mécènescollectionneurs-donateurs, les hommes d'affaire évoqués ont tous créé des universités privées éponymes. Ce n'est qu'après cette phase de fondation d'universités, principalement la décennie 1990, que ces familles ont inauguré, depuis les années 2000, leur «saison fondation de musées».

Trois familles turques occupent le devant de la scène culturelle à Istanbul; les Koç, les Sabanci et les Eczacibasi. Un outsider est venu les rejoindre récemment, qui n'a pas le même profil et qui conteste à ces trois dynasties la première place quant à l'innovation et la créativité; il s'agit de Oguz Özerden et de ses associés, figures de l'intelligentsia turque qui ont fondé ensemble l'université Bilgi et le centre artistique Santralistanbul. La fortune des deux premiers lignages est née du développement économique de l'après-deuxième guerre mondiale, stimulé par les politiques dites de substitution aux importations, l'automobile, l'électroménager, et aussi par l'essor du textile. Quant à la prospérité des Eczacibasi, elle remonte au début $\mathrm{du} \mathrm{xx}^{\mathrm{e}}$ siècle et a pour terreau le secteur pharmaceutique. Ces trois dynasties ont diversifié et élargi considérablement leur champ d'activité depuis les années 1960. Elles figurent aujourd'hui parmi les plus grandes fortunes du monde. Depuis l'année 2000 chacun des trois lignages a créé un musée d'art contemporain à Istanbul. Cette "ère du mécénat» fut précédée d'une phase de "souci philanthropique» durant laquelle leurs initiatives se sont focalisées sur l'éducation et, dans une moindre mesure, sur la santé.

Mais qu'entend-t-on ici par philanthropie, et qu'entendra-t-on par la suite en parlant de mécènes? Si le XVIII ${ }^{e}$ siècle fut célébré comme l'ère des Lumières, le XIX ${ }^{e}$ peut sans

11 - C. Fourier, La fausse industrie morcelée, répugnante, mensongère, et l'antidote, l'industrie combinée, attrayante, véridique, donnant quadruple produit et perfection extrême en toutes qualités, Paris, Bossange Père, 1836, p. 783-784. Fourier continue: "Notre foyer est Constantinople, local favorisé de toutes les perfections». Et voici les éléments qui en font ses "avantages désirables» :

«1. Port gigantesque, aussi commode que magnifique.

«2. Petit fleuve d'eaux douces très pures, placées en sommet du port et suffisant aux besoins.

«3. Remous de curage, contournant balayant le port, et enlevant le superflu des eaux douces.

«4. Pose à demi-centre du grand continent, et en abordage maritime du petit continent.

«5. Local à portée des produits de toutes zones.

«6. Croisée de toutes communications par terre et par mer.

«7. Beauté suprême en sites accidentées, en points de vue locaux et lointains.

"[...] Pourvu de tant d'avantages, ce local sera choisi pour capitale du globe, dès la $3^{e}$ génération d'harmonie; après le temps nécessaire pour rebâtir la ville, la distribuer en phalanges urbaines, qui ne voudront pas de nos maisons malsaines. » 
aucun doute être considéré comme le "temps des philanthropes ${ }^{12}$ ». Cette forme de bienfaisance peut schématiquement se définir comme "le mode d'entraide sociale propre à la période postérieure au désenchantement $d u$ monde, où le déclin de la charité (ou du zekât ${ }^{13}$, ou de la tsedaka ${ }^{14}$ ) n'est encore pas relayé par l'action d'un État social. La philanthropie ne s'exerce pas, comme le fait la charité, pour témoigner de l'amour de Dieu en soulageant la souffrance. Elle se donne pour mission de prévenir plutôt que de guérir. Elle encourage la croissance de la production, l'augmentation des richesses. Elle agit sur l'éducation, la santé, inaugure des modes de contrôle social inédits. Vu sous cet angle, il n'est pas étonnant que les premiers philanthropes français eussent été des acteurs notoires de la Révolution. Ces nouvelles pratiques se diffusent jusque dans les territoires ottomans, où les philanthropes se distinguent au sein des communautés chrétiennes et juives comme des élites non religieuses rivalisant avec le pouvoir des ecclésiastiques et promouvant une éducation dite "moderne". Puissant marqueur social, cette philanthropie étend, à la fin du XIX ${ }^{e}$ siècle, le champ de sa bienfaisance vers de nouveaux domaines, vers les arts et les artistes, la recherche scientifique et l'archéologie. Les philanthropes se font alors mécènes. Réunir des collections d'objets d'art, de peinture, en faire donation à l'État, fonder des musées deviennent dès lors des conduites qui s'imposent à des notables soucieux de succéder à l'aristocratie de $\operatorname{cour}^{15}{ }^{\prime}$.

Il est certain que la philanthropie occupe une place à part parmi les diverses formes d'assistance connues. Aucune autre forme de "bienfaisance» n'a induit autant d'actions d'envergure avec autant d'effets durables. Aucune autre n'a été autant décriée et finalement ignorée en France. Si au XIX siècle Victor Hugo en faisait un motif de critique sociale, le relais fut pris par la sociologie des années 1970 qui a mis la philanthropie en accusation plus pour son caractère normatif que pour avoir été "suppôt du capitalisme». Tandis que dans la littérature anglo-saxonne se sont développées les études sur les thèmes philanthropy/benevolence/beneficence et sur les politiques du care, en France les ouvrages consacrés à ces sujets se comptent sur les doigts d'une main. La période que couvre l'excellent ouvrage de Catherine Duprat ${ }^{16}$ s'achève à la monarchie de Juillet alors que l'action philanthropique donne toute sa mesure durant le long XIX siècle et s'étend sur les deux premières décennies $\mathrm{du} \mathrm{xx}^{\mathrm{e}}$. Cette difficulté ou réticence à constituer la philanthropie en objet d'étude vaut d'être elle-même étudiée.

Normative, la philanthropie l'a été assurément. C'est bien pour cela qu'il est important de l'étudier et l'analyser en la plaçant parmi les autres formes du souci des autres. Cela contribuerait notamment à ne pas confondre la philanthropie

12 - L'expression est de Catherine Duprat : Le temps des philanthropes. La philanthropie parisienne des Lumières à la monarchie de Juillet, Paris, Éditions du CTHS, 1993.

13 - L'ensemble des obligations de charité dans la religion musulmane.

14 - Aumône dans la religion juive.

15 - Voir N. Seni, texte de présentation du colloque international Philanthropes et mécènes dans la ville. Pour une politique culturelle contemporaine, organisé par l'IFEA, l'UMR Études ottomanes et turques (CNRS-EHESS-Collège de France), Institut français d'urbanisme de l'université Paris-VIII et le musée de Péra, Istanbul, 25-28 janvier 2008.

16 - Le temps des philanthropes..., op. cit. 
et le paternalisme qui est une forme de patronage fondée sur la relation individuelle et familiale entre le "bénéficiaire» et le "bienfaiteur». Le paternalisme repose sur l'idée de protection mais aussi de tutelle, comme l'illustre le travail de Claude Beaud sur "Les Schneider au Creusot ${ }^{17}$ ». Aujourd'hui le grand public a pris connaissance de la vogue des fondations (reconnues "d'utilité publique») et des actions philanthropiques d'envergure notamment à l'occasion de l'impressionnante donation de l'américain Warren Buffet à la fondation de Bill Gates qui se consacre à la lutte contre le sida en Afrique. Ces usages font des émules en France où "le nombre de fondations créées en 2007 est supérieur de $30 \%$ au nombre créé en 2001, selon une étude de l'Observatoire de la Fondation de France, publiée mercredi 2 avril [2008]. Ce secteur a dépensé 3,7 milliards d'euros en 2005 , soit $10,4 \%$ de plus qu'en 2001 , en euros constants ${ }^{18}$ ».

Une distinction doit aussi être maintenue entre les notions de mécénat et de sponsoring que l'on peut définir comme le mécénat d'entreprise ${ }^{19}$. Celui-ci doit être considéré comme faisant partie intégrante des stratégies de marketing et de communication des firmes privées, à but lucratif. On peut remarquer parallèlement qu'incités à l'autonomie financière, les grands musées nationaux ont tous développé des compétences dans le fundraising, littéralement "levée de fonds». Cette politique a entraîné la création de services comme «les amis du Louvre», "les amis de Camondo", leitmotiv devenu norme contraignante du management des grands établissements depuis les années 1990. Jacques Rigaud, ancien président de l'Admical, association chargé de promouvoir le mécénat, situe l'émergence en France du mécénat d'entreprise paradoxalement à la période du «doublement des crédits de la culture par Jack Lang, en 1982. Je me souviens, ajoute-t-il, du communiste Guy Hermier nous disant: "Maintenant que l'État s'engage fortement, on n'est plus contre vous" ${ }^{20}$.» Depuis les années 2000 le statut des musées publics s'est transformé pour en faire des entités mieux aptes à susciter et recevoir des dons, et surtout à engager des partenariats avec des entreprises privées.

Mais revenons à Istanbul.

17 - «Les Schneider au Creusot», in E. Aerts, C. Beaud et J. Stengers (dir.), Liberalism and Paternalism in the 19th century. Proceedings of the Tenth International Economic History Congress, Louvain, Leuven University Press, 1990.

18 - "La vogue des fondations et de la philanthropie continue à faire des émules en France», Le Monde, 6-7 avril 2008, p. 11. L'article signé par Annie Kahn précise que la «moitié des sommes est allée dans le secteur de la santé, $31 \%$ ont financé des actions sociales, et $6 \%$ des actions du domaine des arts et de la culture».

19 - Voir aussi les chapitres concernant le don dans la société romaine et l'évergétisme dans Paul Veyne, Le pain et le cirque, Paris, Seuil, 1976.

20 - Michel Guerrin et Emmanuel de Roux, «Entretien avec Jacques Rigaud, ancien président de l'Admical», Le Monde, 14 février 2008, art. cit. 


\section{Les Koç. Précurseurs?}

Le musée Sadberk Hanim, est le premier des musées privés créés à Istanbul. Inauguré en 1988, il porte le nom de l'épouse de Vehbi Koç (1901-1996), industriel, leader de la première génération de la bourgeoisie turque musulmane de l'aprèsguerre $^{21}$. Installé dans deux yali (maisons sur l'eau) qui communiquent par un bâtiment neuf, situé au nord de la rive européenne du Bosphore, à Buyukdere - petit village où ambassades et grandes familles venaient en villégiature dans des propriétés au bord de l'eau -, ce petit musée reste relativement éloigné des divers centres de la ville. Connue sous le nom de «maison Azaryan ${ }^{22}$ », l'une des deux demeures fut achetée comme résidence d'été en 1950 par les Koç. Ce n'est qu'en 1978 qu'ils décidèrent de la transformer en musée. Une première conversion des bâtiments s'effectua, conformément au projet du célèbre architecte turc Sedat Hakki Eldem, entre 1978 et 1980. Le musée se déploie aujourd'hui sur une surface de $400 \mathrm{~m}^{2}$. Y est exposée, entre autres, la collection d'objets archéologiques issus de la période préislamique réunie au début du $\mathrm{xx}^{e}$ siècle par un personnage, Huseyin Kocabas, sur lequel quasiment rien n'a été publié jusqu'à aujourd'hui. En fait les Koç n'acquirent sa collection qu'en 1983. La gamme d'objets qui la constituent s'étend de lampes à huile anciennes à des bijoux, vestiges des civilisations hittites, grecques, byzantines.

Demeuré excentré et de faible rayonnement ce musée peut être considéré comme un coup d'essai, une plateforme expérimentale pour les initiatives Koç dans ce domaine. Deux générations plus tard, des membres de la famille explorent aujourd'hui la possibilité de transférer ce musée sur les bords de la Corne d'Or, territoire auquel la municipalité promet une vocation de "vallée de la culture».

Formé dans les meilleures écoles américaines, amateur d'art, le fils de Vehbi Koç, Rahmi (né en 1938), fonde son musée des Transports, de l'Industrie et des Communications justement sur ces rives de la Corne d'Or, dans le quartier de Hasköy. Le bâtiment restauré pour accueillir le musée est une ancienne église byzantine transformée au XvIII ${ }^{\mathrm{e}}$ siècle en fonderie d'ancres et qui servit par la suite d'entrepôt d'alcools. Rahmi Koç achète la fonderie en 1991, inaugure le musée en 1994, et l'agrandit en faisant l'acquisition, en 1996, des chantiers navals de Hasköy qui venaient d'être privatisés. L'initiative de Rahmi Koç advient au lendemain des expropriations, des destructions d'ateliers artisanaux et d'usines

21 - Premier conglomérat turc en termes de revenus en 2004, le groupe Koç compte 96 filiales en 2004 et emploie environ 60000 personnes; il a généré un revenu de 16,6 millions de dollars américains et un bénéfice net de 379 millions de dollars américains. Ses ventes à l'international représentent $35 \%$ de ses revenus. Les secteurs-clés et les entreprises phare du groupe sont: 1) l'automobile avec les marques Ford, Otosan, Tofas, Türk Traktör; 2) les biens de consommation durable avec la marque Arçelik; 3) l'alimentaire et la distribution avec Migros; 4) la finance avec Koçbank, Koçlease, Koç Allianz; 5) l'énergie avec les firmes Aygaz et Opet. En 2005 le groupe Koç a réalisé trois acquisitions majeures : la banque Yapi Kredi (banque et assurance), les firmes Tansas (distribution) et Tüpras (raffinerie).

22 - Ce patronyme arménien peut correspondre à celui des anciens propriétaires ou à celui de l'architecte. 
des fronts d'eau sur les rives de la Corne d'Or, opération table rase dont se rendit responsable le maire du Grand Istanbul de 1984 à 1989. Friches, ateliers, fabriques furent détruits et remplacés par des espaces verts et des boulevards qui les rendirent accessibles. Ainsi, l'initiative de Rahmi Koç eut pour résultat la reconquête heureuse d'une petite partie des rives de la Corne d'Or, "perle insolite au milieu du chaos". Le succès de son action tient sans doute plus à la sauvegarde du site qu'à l'intérêt de la collection exposée. Cependant les expositions qui ont lieu dans ce musée - comme celle qui présenta en 2006 les dessins de Leonard de Vinci - rencontrent un certain succès, contribuent à son rayonnement et à l'ébauche d'une nouvelle centralité. Le musée des Transports ainsi que le centre culturel Santralistanbul créé une vingtaine d'années plus tard (septembre 2007) et le campus de l'université Bilgi y attenant sont les seules initiatives de reconversion "culturelle» des friches de la Corne d'Or qui se soient révélées pérennes à ce jour.

Réhabiliter des sites anciens, créer, préserver le patrimoine semble avoir été la mission de Rahmi Koç. À Ankara aussi l'homme d'affaires a créé, en 2005, sur les friches d'un caravansérail du Xvi ${ }^{e}$ siècle, le musée Cengelhan de l'industrie. Situé face à la porte du fort d'Ankara ce site représente la seconde initiative associant restauration patrimoniale et création de musée qu'entreprend la Fondation Rahmi Koç des musées et de la culture.

Inaugurés sans campagne publicitaire significative ni battage dans les médias, ces musées Koç - le Sadberk Hanim et celui de Transports et de l'Industrie - n'ont guère programmé à ce jour des événements d'envergure. Ils jouissent d'une visibilité assez discrète.

Si cette première époque du mécénat Koç peut être qualifiée d'expérimentale, de modeste et tâtonnante, elle a cependant présenté un modèle aux autres grandes familles, installant l'idée que des acteurs privés peuvent et doivent initier une certaine patrimonialisation. Le nom des Koç est désormais associé à des opérations de requalification, de patrimonialisation et de préservation de lieux et d'objets anciens. La famille se sert de son statut de leader parmi les élites pour s'ériger en modèle et proposer les «bonnes conduites» à imiter par ceux qui prétendent s'élever au même rang social.

Les établissements artistiques fondés dans les années 2000 feront pâlir le discret rayonnement des musées de la première génération. C'est à Suna Kiraç (née en 1941), fille de Vehbi, fondateur de la dynastie, qu'il revient d'assurer la relève. En 2005 elle inaugure avec son mari, Inan Kiraç, le musée de Péra. Elle l'installe dans les murs de l'Hôtel Bristol, ancien hôtel luxueux fin de siècle à l'abandon, au centre du quartier de Tepebasi, sur la rue Mesrutiyet qui se dénommait aussi jusqu'aux années 1920 la rue des Petits-Champs. Promenade des Européens et des Levantins, cette rue était célébrée par les récits de voyageurs de passage à Contantinople. En effet, Tepebasi se situe à la jonction des anciens quartiers de Péra et de Galata, districts européens d'Istanbul qui abritaient ambassades, cafés, théâtres, banques et grands magasins. En choisissant d'installer musée et collections au cour de ce quartier, en ressuscitant son ancien nom «Péra» pour baptiser leur 
établissement, les Koç-Kiraç annoncent qu'ils l'inscrivent dans le sillage européen d'Istanbul et des arts. La reconversion de l'Hôtel Bristol en musée est confiée à l'architecte Sinan Genim qui ne garde de l'ancien bâtiment que sa belle façade. L'inauguration du musée est marquée par un événement fortement médiatisé: l'achat pour 3,1 millions d'euros, par les Koç-Kiraç, du tableau Le Dresseur de tortues, d'Osman Hamdi $\mathrm{Bey}^{23}$, la plus chère des peintures ottomanes vendues à ce jour aux enchères. À cette vente les Kiraç se sont trouvés en concurrence avec un autre couple, lui aussi fondateur de musée, Oya et Bülent Eczacibasi, à qui l'on doit la création d'Istanbul Modern (voir plus bas). Ces derniers ont enchéri sans succès. Cette confrontation que la presse s'est empressée de relayer signifie que désormais la concurrence pour le leadership parmi les grandes familles turques s'est étendue au terrain des collections d'art et de la création d'établissements culturels.

Avec la Fondation Suna-Inan Kiraç (2003) et le musée de Péra l'action «culturelle» de la lignée Koç passe à la vitesse supérieure. L'ambition n'est plus exclusivement centrée sur la patrimonialisation et la préservation, mais se fixe sur la création artistique. Pas n'importe laquelle. Leurs choix privilégient les peintres ottomans et/ou les œuvres qui se rapportent aux Ottomans. Ainsi, la collection de peintures orientalistes exposée au musée de Péra comprend plus de 300 tableaux d'artistes tant européens qu'ottomans. On y trouve les œuvres du genevois Jean-Étienne Liotard (1702-1789) surnommé le "peintre turc» pour avoir séjourné longtemps à Constantinople, et surtout celles de Jean-Baptiste Vanmour (1671-1737), peintre français d'origine flamande connu pour ses représentations des réceptions d'ambassades et des fastes de la cour ottomane.

Créer des centres de recherche historique sur la ville d'Istanbul ou sur l'archéologie en territoire anatolien est un autre axe de la mission culturelle de ces grandes familles. En octobre 2006 la Fondation a inauguré, toujours à proximité du musée de Péra, sur la même rue, le Centre de recherche d'Istanbul (Istanbul Arastirmalari Enstitusu). Une bibliothèque en fait partie qui est accessible au public depuis juin 2007.

Le couple Koç-Kiraç tente aujourd'hui de racheter - pour 140 millions d'euros - l'immeuble de la télévision d'État (la TRT) situé juste en face de son musée de Péra. Il souhaite y construire un très grand complexe culturel comprenant salles de concerts, théâtre, galeries d'art et centre commercial. L'architecte pressenti pour ce projet, Frank Gehry, a présenté une proposition ambitieuse ${ }^{24}$, tout à fait susceptible de transformer la ligne d'horizon d'Istanbul. Il est probable que le couple de mécènes, influencé par le "miracle» du Guggenheim à Bilbao, vise pour son complexe

23 - Osman Hamdi Bey (1842-1910) est un des pionniers de la peinture ottomane. Il fut l'élève de Jean Léon Gérôme à Paris. À Istanbul, il fonda le musée de l'Archéologie et l'École des beauxarts, aujourd'hui université Mimar Sinan.

24 - Le projet a été présenté au musée de Péra par Özalp Birol, directeur de la Fondation Suna Inan Kiraç, au colloque Philanthropes et mécènes dans la ville: pour une politique culturelle contemporaine (25-28 janvier 2008), organisé sous la responsabilité scientifique de Nora Seni par l'IFEA, le musée de Péra, l'équipe des Études turques et ottomanes (EHESS-CNRS) et l'Institut français d'urbanisme de l'université Paris-VIII. 
culturel une réalisation architecturale qui fasse sensation et qui fonctionne comme un nouveau logo pour Istanbul, à la manière de la tour Eiffel pour Paris.

\section{Stratégie territoriale Suna et Inan Kiraç}

Une caractéristique est commune aux trois grandes initiatives Suna et Inan Kiraç (le musée, le Centre de recherche sur Istanbul, le complexe en projet) : elles sont toutes trois localisées - dans un mouchoir de poche -, sur l'ex-rue des PetitsChamps, à l'ouest du quartier de Péra (aujourd'hui Beyoglu). Colonie génoise du $\mathrm{XIII}^{\mathrm{e}}$ au $\mathrm{XV}^{\mathrm{e}}$ siècle, ce district a regroupé ambassades, représentations européennes, grandes églises et, au XIXe siècle, les écoles fondées par les philanthropes grecs et les diverses congrégations chrétiennes. Il a symbolisé à partir de cette époque le mode de vie occidental auquel aspirait une partie des élites ottomanes. La rue des Petits-Champs s'est couverte d'hôtels de luxe, le Péra Palace, le Grand Hôtel de Londres et justement l'Hôtel Bristol où s'est installé le musée de Péra. Le tissu urbain s'est percé de passages ${ }^{25}$ qui auraient inspiré Walter Benjamin s'il les avait connus; banques, cafés, grands magasins, théâtres se sont multipliés. Le prestige du quartier n'a pas survécu à l'extension de la ville vers le Nord. Son déclin s'accéléra après le pogrom de la nuit du 5 au 6 septembre 1956, où les magasins des commerçants non musulmans furent détruits. Le quartier fut ensuite occupé à partir des années 1960 par les migrants. Depuis les années 1990 un processus lent de gentrification est à l'œuvre - on peut parler d'une "reconquête du centre» menée par l'intelligentsia stambouliote écrit Stéphane Yerasimos ${ }^{26}$ - que devrait accélérer l'installation du musée et des centres culturels Kiraç dans ce périmètre.

Le choix des localisations pour les établissements Kiraç semble dériver d'une stratégie en deux temps. Dans un premier moment, le couple investit un immeuble déchu mais héritier du prestigieux passé européen. Le Bristol est un vestige d'une ère révolue, inscrite dans les mémoires comme âge d'or de la diversité culturelle à Istanbul. En s'y installant le musée de Péra hérite et s'approprie du fameux mythe $\mathrm{d}^{\prime}$ "une mosaïque des peuples et des religions» qui s'attache à l'ancien Istanbul en général et à Péra en particulier. Il évoque savamment et à son tour un luxe très européen et agréablement désuet. Dans un deuxième temps, la notoriété très actuelle de la famille retombe sur l'ancien immeuble, efface les relents de ruine et d'abandon qu'il a pu porter et l'associe à la success story des Koç-Kiraç.

Ainsi se dépose le sceau du mécène sur la ville. Ce mécanisme est ici un moteur important de la requalification du quartier qui désormais ressuscite l'identité européenne d'Istanbul, s'affirme comme district voué aux loisirs, au luxe à l'occidental, à la consommation de biens culturels et artistiques. Néanmoins, la promotion du quartier et sa réhabilitation ne sont pas les objectifs principaux de l'action des Kiraç; elles adviennent incidemment, en sont les conséquences. On le verra plus

25 - Les passages Hazzopoulos, Fresco, Aznavour et Carlmann sont les plus connus.

26 - Stéphane Yerasimos, "Istanbul : la naissance d'une mégapole», Revue géographique de l'Est, t. XXXVIi, n²-3, 1997, p. 189-217, p. 209 
loin, la logique qui commande à leurs engagements culturels relève d'un rôle quasi diplomatique et tente de définir une nouvelle image de la Turquie.

\section{La philanthropie ancêtre du mécénat L'université Koç}

L'appréhension du mécénat et des conduites philanthropiques des Kiraç-Koç serait incomplète si on négligeait de mentionner leur action en faveur de l'éducation et de la santé. Bien avant d'entamer une carrière de créateur de patrimoine-fondateur de musée, la famille avait déjà imposé son leadership à la première génération d'hommes d'affaires turcs de l'après-guerre tant du point de vue du modèle de réussite économique qu'en diffusant des formes de "générosité» qui s'imposèrent comme normes contraignantes à la bourgeoisie montante. Cette "manière de faire» philanthropique est le plus important des «usages» que les Koç furent les premiers à adopter et à propager parmi les nouvelles élites post-républicaines. Vehbi Koç mit ses pas dans ceux des philanthropes du XIX ${ }^{e}$ siècle - européens et américains - et apporta son soutien par des donations en équipements à l'enseignement supérieur et à la médecine.

En 1993 est inaugurée l'université Vehbi Koç sur la rive asiatique, au nord du Bosphore. Elle est fondée sur un modèle essentiellement américain et l'enseignement se fait en anglais. De son immense campus high-tech entouré de forêts on aperçoit la mer Noire. Sa "business school», inaugurée en 1993 a d'ores et déjà acquis une certaine réputation et s'ouvre davantage à l'international, grâce notamment, à une accréditation européenne. C'est la qualité de son «Executive MBA» qui a valu à l'université Koç de figurer parmi les vingt meilleures écoles de commerce européennes, sur la liste publiée par le quotidien allemand Frankfurter Allgemeine Zeitung 27.

Aujourd'hui, au vu des usages de "responsabilité publique» qui ont cours chez les Koç, on peut avancer que l'étape philanthropique qui a coïncidé avec le «règne» du fondateur du groupe (Vehbi Koç) se prolonge parallèlement au développement du mécénat. L'univers de ce nouveau mécénat est d'emblée international. La concurrence dans laquelle s'inscrit la nouvelle génération de mécènes a pour horizon le monde. Construire un patrimoine artistique, préserver le patrimoine historique est l'objectif immédiatement lisible. Mais l'ambition des Kiraç est plurielle : à titre particulier il s'agit bien pour eux d'exister sur la scène internationale des collectionneurs, des fondateurs de musée comme François Pinault, Bernard Arnault ou encore la Fondation Guggenheim. Faire-valoir d'un univers artistique globalisé, musées et collections sont calibrés aux normes internationales. Le second volet

27 - Voir Nicole Pope, «En Turquie, l'université Koç vise le marché oriental», Le Monde, 28 septembre 2004. La correspondante du Monde a interrogé le responsable du diplôme : "Nous voulons internationaliser notre programme et faire de notre université un centre pour l'Europe de l'Est, la Méditerranée orientale, l'Asie centrale et le Golfe", explique Baris Tan, le directeur de la Graduate School of Business. "Pour l'instant, environ $8 \%$ de nos étudiants sont étrangers. Nous voulons augmenter ce pourcentage." " 
de leur mission est d'ordre public, quasi diplomatique et passe par la promotion d'Istanbul comme vitrine de la Turquie, métropole parmi les métropoles du bloc occidental. En témoigne le grand projet de centre culturel confié à Frank Gehry, un des architectes qui avec Jean Nouvel, Zaha Hadid et Tadao Ando ont contribué à établir le paradigme qui commande à l'instrumentalisation des équipements culturels dans l'action territoriale: un grand projet urbain, un musée d'art contemporain, un architecte de renom appelé à réaliser un bâtiment dont l'extravagance fait de l'ombre aux collections exposées. On espère aussi de cette construction qu'elle marque suffisamment les esprits pour se constituer en symbole de la cité, devenir une marque de fabrique, un logo de la ville en question. Est cohérent avec cette visée des mécènes turcs - les Koç-Kiraç n'en ont pas l'exclusivité - l'emplacement choisi pour leurs musées : ceux-ci ne sont jamais situés dans la presqu'île historique d'Istanbul, lieu des monuments et vestiges byzantins ou ottomans qui ont étayé son image touristique - Sainte-Sophie, la Mosquée bleue, le palais de Topkapi etc. Les territoires des nouveaux musées sont d'anciens quartiers européens comme Péra (aujourd'hui Beyoglu), le port d'Istanbul ou les rives de la Corne d'Or qui, avant de se laisser polluer par l'activité industrielle, recevaient à la fin du XIX siècle les promenades sélectes des dames de la bonne société ottomane.

\section{Les seconds se hissent au premier rang Les Sabanci}

Principale rivale, mais aussi partenaire des Koç, la famille Sabanci est originaire du Sud-Est anatolien où elle a fait fortune dans la culture du coton et dans le textile. Si le groupe Sabanci est aujourd'hui coté en Bourse, il faut savoir que $80 \%$ de ses actions sont détenues par les membres de la famille, dont la fortune est estimée par la revue américaine Forbes à 3,2 milliards de dollars. Le chiffre d'affaires consolidé du groupe - associé à des firmes comme Carrefour, Du Pont, Toyota, BNP-Paribas, Hilton Group, Philip Morris, IBM - s'élevait à 7,3 milliards de dollars en 2003, pour un bénéfice net de 583 millions.

L'université Sabanci est située à Tuzla, à une quarantaine de kilomètres de l'hyper-centre, dans une zone industrielle à l'extrême sud de la rive asiatique, au bord de l'autoroute reliant Istanbul à Ankara. Elle a été inaugurée en 1994. Pour leur université les Sabanci ont déclaré viser l'excellence; ils lui ont assigné la mission d'être une "université du monde» (world university) fondée pour "créer et se développer ensemble» ${ }^{28}$. L'équipe dirigeante insiste sur l'indispensable caractère novateur de l'établissement et clame son refus de prendre modèle sur toute autre institution similaire, à l'étranger ou dans le pays. L'enseignement - en anglais - a débuté en octobre 1999. Le campus, très moderne, accueillait, en 2007, quelque 2500 étudiants.

28 - Voir le site de l'université : http://www.sabanciuniv.edu/eng/anasayfa/anasayfa.php. 


\section{Collections et musée}

Sakip Sabanci (1933-2004) était celui de la fratrie - cinq frères - qui «communiquait» le plus; il entretenait d'excellentes relations avec la presse. Celle-ci s'est faite le relais de son intérêt pour les arts ottomans et a attiré l'attention de l'opinion publique sur ses collections. Personnage haut en couleur, très mondain, il avait repris, pour l'habiter, la somptueuse villa sur la rive européenne du Bosphore, adossée au parc de Emirgân (Atli Kösk ou la Villa équestre), que son père avait achetée aux héritiers du prince Mehmed Ali Hasan, petit-fils du khédive Ismail Pasa. L'histoire de cette propriété témoigne de la période de la fin de l'Empire, des aléas du dernier siècle ottoman ${ }^{29}$. En 1951 Haci Ömer Sabanci l'achète aux fils du prince pour en faire la résidence d'été de sa famille. Après sa mort (1966) la villa est rachetée par la Ömer Holding Company en 1975. De 1969 à 1999 son fils Sakip et sa famille s'y installent. La maison, la collection d'art et le mobilier ancien auxquels elle servait d'écrin sont cédés en 1998 pour une période de quarante-neuf ans à l'université Sabanci pour qu'elle y établisse en 2002 le musée Sakip Sabanci de l'université Sabanci. Cette collection témoigne de cinq cents ans d'art calligraphique et contient quelque 400 objets parmi lesquels des objets de culte, des corans, des manuels de prière ainsi que des éléments de vaisselle impériale, des décrets du Sultan (des hats), des inscriptions cérémoniales du palais impérial, des cahiers de poésie.

Depuis 2005 ont été organisées dans ce musée les grandes expositions qui ont inauguré une nouvelle ère dans la vie artistique en Turquie. En $2004 \mathrm{M}^{\text {me }}$ Nazan Ölçer, anciennement conservatrice du musée des Arts islamiques, prend la direction du musée Sabanci qui engage également celle qui fut la première femme à diriger le musée du palais de Topkapi, Filiz Cagman. Reconnues sur la scène internationale, distinguées par divers prix pour leurs compétences, ces deux femmes installent sur une nouvelle orbite le cours de la vie muséologique à Istanbul. Sitôt ses nouvelles fonctions prises, Nazan Ölçer organise la première grande exposition (novembre 2005-mars 2006) consacrée en Turquie à un artiste occidental avec 135 œuvres de Picasso - dont certaines jamais montrées au public depuis sa mort - essentiellement des toiles mais aussi des dessins, des sculptures ou des céramiques ${ }^{30}$. Dotée

29 - Entre 1848 et 1884 la demeure fut successivement la propriété de Süleyman Re'fet Pasa, de Musevi Hoca Misak, de Adile Hanim, l'épouse de Resid Pasa, grand vizir qui conduisit les réformes de l'administration ottomane (le mouvement des Tanzimat), de Küçük Mehmed Ali Pasa d'Égypte, de Mustafa Naili Pasa, de Maksudzade Simon Bey, du khédive Ismail Pasa, du gouvernement égyptien, et du khédive Mehmed Tevfik Pasa. En 1884 il fut acheté par le Trésor ottoman pour le compte du sultan Abdülhamid II et offert au roi du Monténégro Nicola I. Pendant les trente années suivantes, il servit de résidence royale et d'ambassade du Monténégro. Redevenue propriété du gouvernement ottoman en 1913, la villa est vendue à Behiye Sultan, la petite-fille du sultan Mehmed V Resad. En 1925, la demeure en ruine est achetée par le prince Mehmed Ali Hasan, petit-fils du khédive Ismail Pasa. Il fait construire par l'architecte Edouard de Nari le bâtiment actuel, qui restera inhabité pendant plusieurs années jusqu'à ce que la princesse Iffet, fille du prince Mehmed Ali Hasan, en fasse sa demeure en 1944.

30 - " "En réalité, précise Nazan Ölçer, ce n'est pas moi qui ai eu l'idée de cette exposition. M. Sabanci, qui voyageait beaucoup, avait visité de nombreuses expositions sur l'artiste. Il avait été impressionné par l'œuvre, par sa profusion et par le nombre de visiteurs que cela fascinait. Un 
d'un budget publicitaire pharaonique l'exposition est très réussie. Elle attire une foule qui n'hésite pas à se rendre jusqu'à Emirgân, quartier excentré et plutôt mal desservi, mais plus proche du centre que ne l'est le musée Sadberk Hanim situé sur la même rive du Bosphore. Pendant trois mois 250000 personnes vont consentir à des trajets et attentes de plusieurs heures pour visiter l'exposition. Ainsi, le quartier qui se distribue autour de l'«échelle» de Emirgân ${ }^{31}$ se "rapproche» du cour de la ville, il devient, dans la géographie imaginaire des stambouliotes, non plus seulement un lieu de promenades familiales et dominicales ${ }^{32}$ (réservé à ceux qui disposent d'une voiture) mais aussi un espace de loisirs artistiques. On peut s'interroger sur la pérennité de cette nouvelle vocation d'Emirgân. La notoriété du musée engendre-t-elle des initiatives de la part des pouvoirs publics pour améliorer l'accessibilité de ce district? Toujours est-il qu'indifférent aux insuffisances du réseau viaire qui le dessert, le musée multiplie les grandes expositions à une cadence impressionnante : à Picasso ont succédé Rodin ${ }^{33}$ (été 2006), Genghiz Khan (automne 2006), Salvador Dali (automne 2008) et Joseph Beuys (automne 2009).

En 2007, les ambitions du musée croisent la nouvelle politique du Louvre qui désormais favorise les partenariats avec des établissements privés à l'étranger. De cette rencontre naît une convention entre les deux établissements. Quelques mois après la signature du contrat pour la construction du "Louvre des sables » à Abou Dhabi qui remua l'opinion française, le 20 mars 2007, M me Güler Sabanci, présidente du conseil d'administration de l'université Sabanci, signe avec Henri Loyrette, président-directeur du musée du Louvre, une convention de collaboration scientifique et culturelle, qui prévoit la création, fin 2007, d'un Center for Museum Studies au sein du musée Sabanci. À partir de 2008, le musée du Louvre et ce centre doivent partager régulièrement «leurs expériences dans les domaines de l'accueil et de l'accessibilité des visiteurs, selon leur diversité linguistique et culturelle; de l'accompagnement des visiteurs : visites-conférences, audioguides publications...; des actions éducatives et pédagogiques en direction de publics ciblés : écoles, salariés des entreprises, associations-relais, artistes...; des politiques tarifaires et de fidélisation et enfin des outils d'étude et d'analyse des publics ${ }^{34}$ ».

peu avant sa mort, il avait décidé de bâtir un important musée et souhaité que la première exposition qui s'y tiendrait soit consacrée à Picasso." C'est chose faite. "Avoir choisi Picasso pour une première grande exposition d'un peintre occidental à Istanbul est un bon choix poursuit Nazan Ölçer. D'abord parce que c'est un nom connu, universel. Je crois au succès de cette manifestation. Nous avons déjà reçu un nombre considérable de réservations de toute la Turquie. Et je ne pense pas que le public soit dérouté. D'autant que nous avons pris soin de montrer toutes les périodes de son activité artistique. La Turquie, pays à la population jeune, doit s'ouvrir, évoluer, et il n'y a pas de meilleur exemple d'évolution et de remise en question que chez Picasso.» (H. de SaintHilaire, «Pablo Picasso sur le Bosphore», Le Figaro, 29 novembre 2005, en ligne à l'adresse suivante : http://turquieeuropeenne.eu/article917.html)

31 - L'«échelle» de Emirgan, ou débarcadère, en service de 1855 à 1989, a été réouverte en novembre 2001 en présence de Sakip Sabanci.

32 - De grands cafés en plein air, traditionnels et modestes, occupent une partie du bord de mer à Emirgân et jouxtent l'entrée du musée Sabanci.

33 - Pour financer cette exposition qui réunissait 203 des sculptures les plus célèbres de Rodin comme Le Baiser ou Le Penseur, le musée Sabanci s'est associé à une banque turque, l'Akbank. Le catalogue en français et en turc a été édité grâce à la collaboration de l’Institut culturel français à Istanbul.

34 - Communiqué de presse du 4 avril 2008, 
En mai 2008 le musée Sabanci accueille l'exposition Istanbul, Isfahan, Delhi - Les empires de l'Islam $\mathrm{XV}^{e}$-XVIII ${ }^{e}$ siècle, qui rassemble "près de 200 ouvres des collections du département des Arts de l'islam du Louvre - l'une des plus riches du monde ${ }^{35}$ ».

Nul doute que cette convention avec le Louvre soit un atout qui favorise les Sabanci. Mais les règles qui s'appliquent dans ce domaine des collectionsdonations - fondations de musée se diffusent rapidement par la concurrence et se transforment en normes contraignantes de conduite pour tous ceux qui partagent le même terrain. Gageons que d'autres musées nationaux français exploreront les opportunités de nouvelles ressources financières et de conventions avec les musées privés d'Istanbul, infléchissant la politique des grands mécènes turcs, suscitant des conventions - de prêts d'œuvres, d'organisation d'expositions - avec ces établissements stambouliotes "émergents " 36 .

\section{Les Eczacibasi}

Contrairement aux Koç et aux Sabanci qui ont fait fortune après la deuxième guerre mondiale, les Eczacibasi se distinguent à Izmir parmi les familles de notables dès le début $\mathrm{du} \mathrm{xx}^{\mathrm{e}}$ siècle. Leur patronyme indique la nature de leur activité principale: Eczacibasi signifie en turc "pharmacien en chef». Les récits qui retracent la biographie de Suleyman Ferit Bey (Eczacibasi) (1885-1973) insistent sur son statut de premier pharmacien à Izmir en possession d'un diplôme universitaire. En effet, le fondateur de la lignée consacre ses premières années d'exercice à l'hôpital des déshérités d'Izmir. C'est là peut-être que commence à se tisser une fibre philanthropique chez ce jeune chimiste. Ses hagiographes soulignent son dévouement aux malades pendant les années de la première guerre mondiale, années de fortes migrations vers Izmir, d'épidémies de cholera et de typhus, de malnutrition. Entre 1950 et 1990, l'activité - encore principalement pharmaceutique - de son groupe s'étend à la production de matériaux de construction, au secteur de la papeterie, à la finance, aux technologies de l'information.

À la différence des deux lignages précédemment cités, la famille Eczacibasi ne développe quasiment pas de stratégie éducative mais s'oriente très tôt vers le domaine culturel. Et dans ce secteur son engagement ne s'exprime pas tout de suite par la fondation de musées mais il passe par la création d'événements artistiques qui prennent rapidement place dans l'agenda mondial des manifestations culturelles: le Festival international de musique d'Istanbul et la Biennale d'Istanbul. C'est en 1973 que Nejat Eczacibasi (1913-1993), fils de Süleyman Ferit Bey, prend l'initiative de créer la Fondation pour la culture et les arts d'Istanbul, l'IKSV (Istanbul Kültür ve Sanat Vakfi), qui fonctionne depuis comme l'acteur principal de l'événementiel culturel et artistique à Istanbul. Le premier festival - de musique - est organisé cette même année. En 1977 la Fondation s'inscrit

35 - Ibid.

36 - Conservateurs et émissaires des musées parisiens se pressaient en septembre 2007 à la Biennale d'Istanbul aussi pour y rencontrer les collectionneurs et mécènes turcs. 
parmi les membres de l'Association européenne des festivals. Suit, à partir de 1982, l'organisation annuelle des Journées du cinéma qui fonctionnent à guichet fermé. Le succès de cette manifestation induit une nouvelle organisation, et les Journées deviennent en 1989 le Festival international du cinéma à Istanbul. À partir de 1994 le Festival international d'Istanbul se divise en un Festival international de jazz d'Istanbul et un Festival international de musique. La Biennale qui se déroule en de multiples points de la ville, des gares de banlieue, des rues dévastées, le Rock'n Coke, le festival Now, un festival de théâtre, etc. sont aujourd'hui les rendez-vous internationaux que l'IKSV a ajoutés à la panoplie des événements qu'elle a instaurés en «rituels urbains» d'Istanbul. Cette année 2009, l'IKSV est coordonnatrice avec Culturesfrance des événements de la Saison culturelle turque en France.

Si les Eczacibasi n'ont pas fondé d'universités comme les Koç ou les Sabanci, ils ont créé en 1959 le prix de la Recherche scientifique et médicale. Cette distinction a contribué au financement de près de deux cents projets de recherche médicale et à l'octroi de plusieurs dizaines de bourses d'études. Dans le sillage de ce prix s'est constitué un véritable espace de débat portant sur les enjeux contemporains en matière de santé publique et de médecine. Bien qu'engagés dans l'éducation et la recherche à travers leur Fondation turque pour l'éducation (1966), les Eczacibasi ont concentré leur énergie sur le développement des arts et de la culture politique. Constituer un univers d'hommes d'affaire turcs relativement indépendants de la haute bureaucratie fut un objectif permanent de Nejat Eczacibasi. En 1954 il est le co-fondateur de l'Institut de gestion de l'université d'Istanbul et de l'Association turque de management. En 1961 il travaille à fonder le Conseil des études économiques et sociales qui deviendra plus tard la très influente organisation indépendante de recherches stratégiques, la Fondation turque des études économiques et sociales (TESEV). Il est l'un des principaux fondateurs de l'association des patrons d'entreprises turques, la TUSIAD. Cette institution n'a cessé de donner des preuves de son indépendance, notamment en publiant les résultats d'un rapport qu'elle avait commandé sur l'état de la démocratie en Turquie, y compris sur la question kurde ${ }^{37}$.

Il faut ajouter à ce tableau ce que la vitalité du cinéma turc contemporain doit au jeune frère de Nejat, Sakir Eczacibasi. Diplôme en chimie à l'instar de son aîné, Sakir (né en 1929) commence sa carrière en se distinguant comme photographe amateur, amoureux du cinéma. Il dote Istanbul de sa première cinémathèque en 1965. Les cinéphiles stambouliotes ont pu ainsi visionner dès leur sortie en Europe, les films de Fellini, de Milos Forman et d'Ingmar Bergman. En 1980 il crée à Istanbul les Journées internationales du cinéma qui s'institutionnalisent en festival international quelques années plus tard. Depuis 1993 il préside le conseil d'administration la Fondation pour la culture et les arts d'Istanbul (IKSV). À la tête de cet organisme qui fonctionne aujourd'hui comme un ministère de la culture, il met en œuvre une politique qui situe Istanbul sur l'orbite des manifestations

37 - B. Tanör, Demokratiklesme Raporu [Rapport sur le processus de démocratisation], Istanbul, TUSIAD, 1999. 
internationales artistiques et culturelles. La ville qu'il promeut est moins la ville historique et patrimoniale, célèbre pour ses vestiges byzantins, son architecture, ses palais ottomans et ses citernes antiques, qu'une plaque tournante de l'art contemporain avec son cinéma, ses musiques, ses festivals, ses biennales et ses colloques internationaux. Si l'objectif affiché par Sakir Eczacibasi est de diffuser les arts et de les rendre accessibles aux stambouliotes, son ambition est plus ample. Il s'agit moins de créer une nouvelle place pour la Turquie dans «le concert des nations civilisées" - selon la formule fétiche du XIX ${ }^{e}$ siècle qui rappelait aux États leur devoir de promouvoir le Progrès et le "rang" de leur nation -, que de faire en sorte qu'Istanbul existe et compte au sein du réseau des métropoles du monde. Si les Eczacibasi souhaitent bien contribuer à l'intégration de la Turquie à l'Union européenne ${ }^{38}$, l'instrument qui sert ce dessein, à savoir cette nouvelle façon de promouvoir Istanbul, est devenue une visée en soi, autonome et dominante. Dans ce domaine, la Fondation pour la culture et les arts d'Istanbul (IKSV) joue un rôle incontestable. En 2003 elle a reçu le prix du Forum européen de la Culture, distinction octroyée par l'Union européenne à des "personnes ou organismes œuvrant pour le dialogue interculturel et la tolérance». L'IKSV a été la cheville ouvrière de la coordination d'une multitude d'initiatives visant à faire élire Istanbul capitale européenne de la culture en 2010.

La Biennale d'Istanbul est certainement la manifestation artistique turque la mieux connue et la plus célébrée sur la scène internationale. Interrogé par un journaliste du Monde, Robert Storr, directeur de la Biennale de Venise en 2007, déclarait à propos de la Biennale d'Istanbul organisée par Charles Esche et Vasif Kortun : "J'étais très impressionné par leur exposition et j'ai ressenti que cette vitalité devrait être montrée au centre de la Biennale [de Venise] ${ }^{39}$. " Robert Storr répondait ainsi au chroniqueur qui lui demandait si en créant un pavillon turc à la Biennale de Venise il ne favorisait pas l'adhésion de la Turquie à l'Union européenne; Storr précisait : "Le retranchement nationaliste en Turquie comme en Europe est vraiment inquiétant. J'espère modestement exprimer ainsi mon soutien à la culture contemporaine turque ${ }^{40}$. " C'était bien le but poursuivi par Nejat Eczacibasi au moment où il initiait la Fondation pour la culture et les arts d'Istanbul : transformer par-delà l'image de la ville-vitrine, l'image de la Turquie. Grâce à la biennale, Istanbul se trouve associée à Venise et à sa vitalité dans les arts contemporains. Cette façon de confier à une manifestation artistique la tâche de représenter une ville n'est d'ailleurs pas récente. L'exemple le plus patent est sans doute celui du Festival de Salzbourg. Sur la réputation de cet événement musical se sont condensés successivement et depuis le début du $\mathrm{xx}^{\mathrm{e}}$ siècle des enjeux d'identité nationale et politique. Après avoir été une vitrine de l'idéologie nazie (de 1938 à 1945) le festival est devenu, pour les Américains qui administraient la ville au lendemain de la seconde guerre mondiale, «un

38 - Voir l'interview de Sakir Eczacibasi dans le quotidien Aksam: «Pazartesi röportajlari», 13 novembre 2006.

39 - H. Bellet, «Rencontre avec l'Américain Robert Storr, directeur de la Biennale de Venise. "Les biennales d'art contemporain ne sont pas des concerts de rock" ", Le Monde, 7 juin 2007.

40 - Ibid. 
moyen $[\ldots]$ d'émettre un signe fort de la construction d'une Autriche républicaine, démocratique et dénazifiée $[\ldots]^{41}$ ».

À Istanbul les actions de l'IKSV, de la Biennale en particulier, sont porteuses de missions plurielles: promouvoir, diffuser, rendre accessible l'art contemporain; transformer l'image d'Istanbul pour la faire exister dans le champ de la concurrence des métropoles; faire avancer la Turquie vers l'Union européenne, confirmer son identité de pays du bloc occidental. La ville ainsi promue et instrumentalisée n'est pas l'Istanbul-monument, la cité des vestiges historiques pavée d'églises byzantines, de chefs-d'œuvre de l'architecture ottomane et de l'art islamique. C'est une place qui a pour ambition d'exister parmi les villes que leur vitalité dans les arts contemporains pousse sur le devant de la scène internationale, au cœeur du réseau des métropoles du monde.

Une des pierres posées pour édifier cette nouvelle identité urbaine est certainement le musée Istanbul Modern, inauguré en décembre 2004 grâce aux efforts conjugués de Sakir Eczacibasi et de Oya et Bülent Eczacibasi. Premier musée d'art contemporain digne de ce nom en Turquie, il a été construit sur un des entrepôts en friche de l'ancien port d'Istanbul, de l'autre côté du bras de mer qui le sépare de la péninsule historique où les touristes se pressent pour visiter le palais de Topkapi et Sainte-Sophie. Ces touristes incluront-ils désormais Istanbul Modern dans leur "circuit»? Aucune enquête n'a produit à ce jour des résultats probants sur cette question. Toujours est-il que ce musée qui se déploie sur une superficie de $8000 \mathrm{~m}^{2}$ vise une reconnaissance internationale immédiate, ambition dont témoigne, entre autres, le choix des conservateurs engagés.

La reconstruction en musée de l'entrepôt $n^{\circ} 4$ fut confiée au cabinet Tabanlioglu Architecture, celui-là même qui a conçu le centre culturel Atatürk, mammouth rectangulaire en centre-ville qui abrite l'Opéra, le Ballet et l'Orchestre philharmonique de l'État. Le coût de l'opération Istanbul Modern est évalué à 6,5 millions d'euros. On y attend un million de visiteurs par an. Le groupe Eczacibasi n'a financé qu'une partie de l'investissement et a assuré la direction du projet. Une nouvelle fondation a été créé en 2005, qui dirige désormais Istanbul Modern. La plus grande partie des œuvres exposées - 8000 pièces au total - provient des collections privées, la collection de la Is Bankasi, la plus importante des banques non gouvernementales, la collection Oya et Bülent Eczacibasi, celle de Nejat Eczacibasi. Certaines œuvres sont issues des fonds du musée d'Art moderne d'Istanbul et du musée de la Peinture et de la Sculpture d'Istanbul. Les entreprises Avea et Hedef Alliance ont concouru au financement. Ont également collaboré au projet la Deutsche Bank et le Guggenheim de Berlin.

41 - A. Charnay, «Les enjeux diplomatiques du Festival de Salzburg», in J.-M. Tobelem, L'arme de la culture. Les stratégies de la diplomatie culturelle non gouvernementale, Paris, L'Harmattan, 2007, p. 141. A. Chamay poursuit: "Après la signature du traité d'État en 1955, le Festival de Salzbourg tient une place de choix dans la construction d'une identité nationale fondée sur une spécificité culturelle où la musique est prédominante. Une partie de l'histoire de l'Autriche est occultée au profit du mythe du premier pays victime du nazisme.» 
L'histoire de ce musée est édifiante, elle raconte l'évolution des relations entre sphères privées et publiques dans le domaine des arts et de la culture. Les Eczacibasi avaient tenté, dès la fin des années 1980, de transformer en musée d'art contemporain les locaux en friche d'une ancienne usine textile, la Fezhane ${ }^{42}$, située sur les bords de la Corne d'Or; la reconversion avait été confiée à Gae Aulenti, l'architecte du musée d'Orsay. Mais la municipalité CHP (Cumhuriyet Halk Partisi / Parti républicain du peuple: parti politique à tradition étatiste créé par la bureaucratie civile dès les premières décennies de la République) n'avait pas délivré les autorisations nécessaires. Quelques mois plus tard le leader du parti «islamo-conservateur», Recep Tayyip Erdogan (Premier ministre depuis 2003), était élu maire d'Istanbul. Bien qu'issu de la mouvance "islamiste», il soutint le grand projet d'un musée d'art contemporain sur le site de l'ancien port, demandant en contrepartie, d'avancer de cinq mois l'inauguration, initialement prévue pour début 2005. La cérémonie se déroula donc quelques jours avant le17 décembre 2004, date à laquelle la Commission européenne devait décider de l'ouverture des négociations d'adhésion de la Turquie à l'Union européenne. On projeta en direct sur les murs blancs du musée les messages de félicitations de Jacques Chirac, Tony Blair et Gehrard Schröder saluant l'événement comme un témoignage de la vocation occidentale et européenne de la Turquie contemporaine. "Le Premier ministre a immédiatement perçu le sens symbolique de ce musée, confiait Bülent Eczacibasi dans une interview à la presse. À un moment où nous essayons de montrer à l'Union européenne que nous sommes culturellement des occidentaux autant que des orientaux, ceci en est une importante illustration.»

L'instrumentalisation de telles inaugurations par la politique étrangère turque (ou doit-on dire par la communication?) ne s'arrêtera pas là. Toujours sommé de faire la preuve de son appartenance au bloc occidental, Recep Tayyip Erdogan a saisi tout le parti qu'il pouvait tirer de ces lieux qu'éclairent les projecteurs du monde entier : ils dissipent les soupçons d'anti-occidentalisme qui pèsent sur son gouvernement et maintiennent Istanbul dans le champ de la compétition entre métropoles mondiales. Ces musées qui exposent la production de la fine fleur de l'art contemporain opèrent une intégration virtuelle de la Turquie à l'Union européenne à travers sa vitrine, Istanbul. Ainsi, le parti islamo-conservateur s'est approprié les projets des grandes familles de philanthropes/mécènes. Dorénavant les dates d'inauguration des musées privés sont décalées, reculées, avancées pour que le Premier ministre puisse y participer et apparaître comme un acteur majeur de l'opération. Ainsi en a-t-il été de Santralistanbul (voir section suivante) dont l'ouverture a été avancé de six mois pour que Recep Tayyip Erdogan puisse l'inaugurer le 8 septembre 2007, juste avant son départ pour l'Europe, à la veille d'une délicate décision de l'Union européenne concernant la Turquie.

Contrairement à la Tate Modern dont il s'inspire, Istanbul Modern ne s'inscrit au cœur d'aucun grand projet d'aménagement. Les docks de l'ancien port d'Istanbul

42 - Fezhane : littéralement lieu où l'on fabrique le fez, cette coiffe en feutre ornée d'une frange que portaient les hommes ottomans. 
font l'objet de convoitises de tous bords, car le site jouit d'un emplacement exceptionnel, en bordure du quartier de centre-ville qu'est Galata et face à la presqu'île historique. Aucun des projets et des adjudications internationaux pour son aménagement n'a pu aboutir à ce jour. Néanmoins, la dernière en date, l'adjudication pour GalataPort remportée en 2005 par un consortium israélien, a bien failli se réaliser. Le projet, qui prévoyait la construction d'un quai de $1200 \mathrm{~m}$ de long pour l'accostage de grands bateaux de croisières et cinq hôtels de luxe, effaçait Istanbul Modern et l'entrepôt $\mathrm{n}^{\circ} 4$ de la carte. Les promoteurs incitaient la direction du musée - via les médias - à déménager dans un môle récemment construit au nord de la ville. Soulevant un véritable tollé, notamment de la part de la très puissante Chambre des architectes d'Istanbul, le projet GalataPort a été annulé pour vice de forme et la question du maintien d'Istanbul Modern sur les lieux ne se pose plus dans l'immédiat.

Un cas à part : les créateurs de l'université Bilgi et de Santralistanbul

Celui qui a pris l'initiative de fonder en 1996 l'université Bilgi ne fait pas partie des grandes familles turques. Les fonds qui ont servi à édifier cette université proviennent principalement d'une fortune tout à fait récente, issue de l'exploitation d'une ligne téléphonique qui fut «rose» à l'occasion. L'heureux initiateur de cette hot line, Oguz Özerdem, était au moment des faits au début des années 1990 un tout jeune homme - il est né en 1963 - qui venait de terminer son master en tant que boursier du gouvernement turc à l'université de Cambridge (1991) au sujet des relations entre la presse, la politique et l'opinion publique. Ce conte de fées moderne est d'autant plus édifiant que fortune faite, le jeune homme la consacre immédiatement à des projets éducatifs. Il crée à Istanbul dès 1993 une société anonyme, Bilgi Education (Bilgi Egitim AS). Avec le concours de deux établissements anglais, la London School of Economics et l'université de Portsmouth, cette société établit dans un premier temps l'Istanbul School of International Studies. Et lorsque la législation turque change pour autoriser la création d'universités par des fondations à but non lucratif, Oguz Ozerdem restructure son établissement qui devient alors en 1996 l'université Bilgi. Le jeune établissement promeut des valeurs partagées telles que la tolérance, l'ouverture d'esprit, le «respect de la diversité des individus qui ont des styles de vie, des croyances et des modes de pensées différents à l'intérieur de la mosaïque des valeurs universelles contemporaines ${ }^{43}$ ». Il exprime en 2005 sa volonté de "maintenir des liens étroits avec les différents segments de la société turque ${ }^{44}$ », en prenant le risque d'accueillir dans ses murs le colloque sur l'histoire de la "question arménienne». La notion d'innovation figure en bonne place dans le matériel de communication de l'université Bilgi. Mais, contrairement à l'usage qui en est fait par les universités Koç ou Sabanci - où, suivant les techniques managériales américaines, elle évoque les conditions d'amélioration en performances techniquement mesurables -, cette notion renvoie ici à la créativité - principalement artistique - et à «l'émancipation »

43 - D. Behar Les universités privées d'Istanbul, Istanbul, IFEA (Dossiers de l'IFEA, 10), 2003, p. 22.

44 - Ibid. 


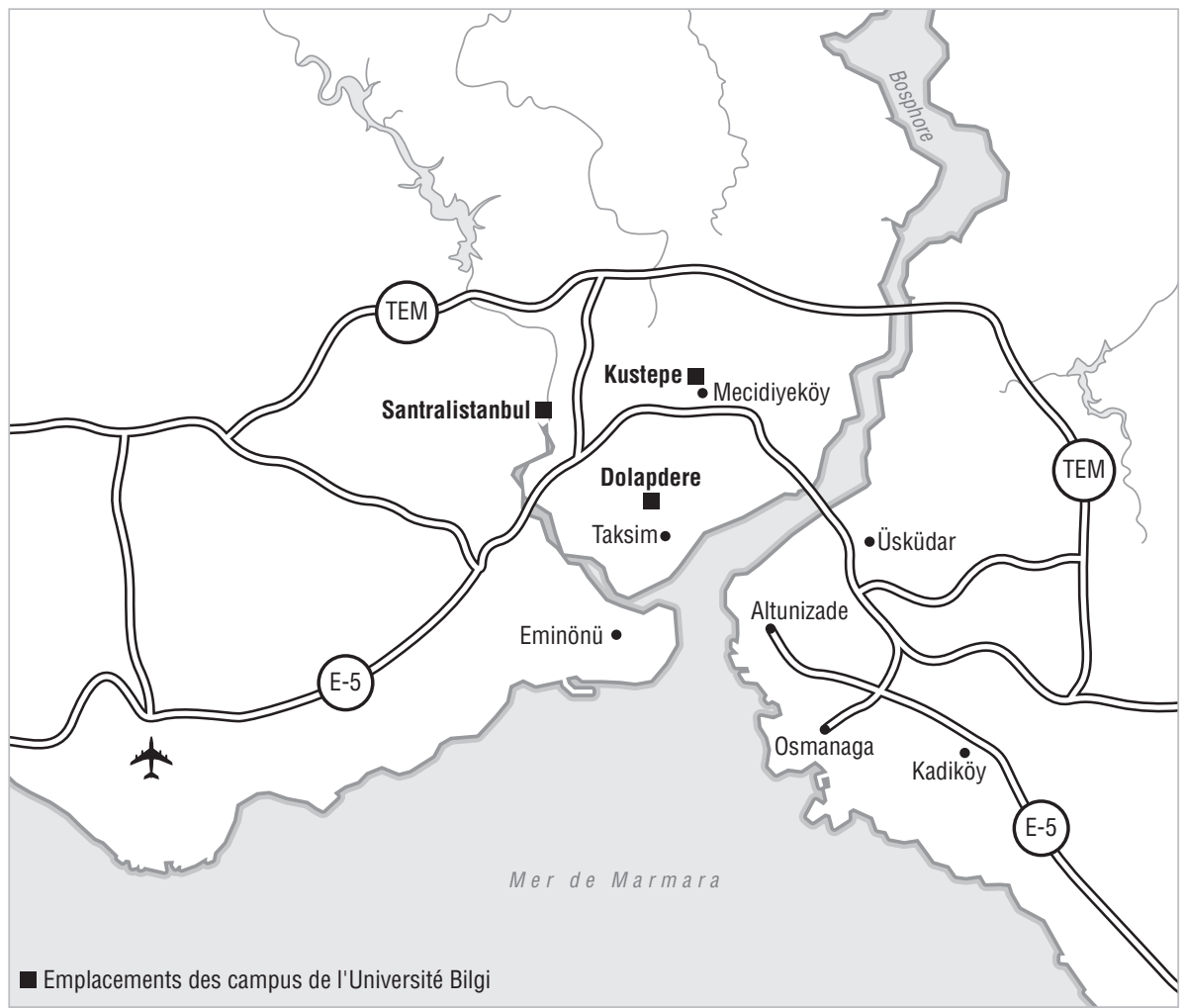

LES CAMPUS DE L'UNIVERSITÉ BIGLI

(des méthodes obsolètes et sclérosées d'apprentissage). Aujourd'hui cette université possède trois campus dans la métropole: Kustepe, Dolapdere et un troisième qui est relié à Santralistanbul, ouvert depuis septembre 2007 tout au fond de la Corne d'Or (Haliç). En 2006-2007, elle comptait 9546 étudiants inscrits, dont près de 2000 boursiers de l'établissement.

La sensibilité urbanistique des créateurs de Bilgi est le principal trait qui les distingue des autres initiateurs d'université. La réhabilitation des quartiers dans lesquels ils installent leurs campus est un des éléments dont ils font une marque de fabrique. Le campus de Kustepe est situé dans un quartier très modeste, sur la rive européenne. David Béhar, qui a réalisé une étude sur les universités privées d'Istanbul comme nouveaux espaces sociaux, précise que le maire de la municipalité (Sisli) dont relève ce campus a soutenu le projet. Le directeur général de la Fondation explique que le choix de l'emplacement relève de la "politique de l'université [dont] l'objectif est de s'intégrer à la vie du quartier de Kustepe et de le faire évoluer peu à peu ${ }^{45}$ ". David Béhar nuance ces intentions au vu de 
l'architecture du campus de Dolapdere, dans le quartier Tarlabasi, quartier déchu en bordure de Péra que les stambouliotes associent aujourd'hui à la pauvreté et à l'insécurité. Bien que disant souhaiter intégrer le bâtiment principal de l'université au quartier, la Fondation Bilgi "a mis en œuvre une volonté d'enfermement digne d'une cité privée ${ }^{46}$ ». Oguz Ozerden se serait "battu avec l'architecte pour que le mur d'enceinte soit le plus bas possible, afin que les passants puissent voir de l'extérieur à quoi ressemble l'université, et pour que les bâtiments ne soient pas trop hauts afin de ne pas dénaturer le quartier. ». Les murs d'enceinte n'en font pas moins cinq mètres de haut, le bâtiment aveugle, sans fenêtre sur l'extérieur, dialogue peu avec le voisinage, et les étudiants pénètrent dans le campus par une entrée quelque peu dissimulée et que garde un service de sécurité. Julien Grouiller conclut que "les pensées sécuritaires semblent réduire la portée du lien que souhaite créer cette université avec son environnement proche $e^{47}$ ». Néanmoins il ajoute plus loin que la Société financière internationale (SFI) estime à plus de 5 millions de dollars les sommes «qu'en 2001 la Fondation Bilgi a déjà dépensé [...] pour les quartiers où elle est située au travers de ses différentes actions ${ }^{48}$ ». On apprend par la SFI que ces dépenses pour le quartier ont concerné des stages de formation d'anglais, de comptabilité, de cours pour devenir instituteur et surtout que la Fondation Bilgi a fait donation d'une école primaire à la municipalité. Sans compter les petites entreprises de services aux étudiants qui ont fleuri dans le voisinage des campus et les services publics de transport et de logement qui s'y sont implantés ${ }^{49}$.

À la manière de la Tate Modern, Santralistanbul est bâtie sur les friches de l'ancienne usine éléctrique Silahtaraga, transformée ici en complexe comprenant un musée d'art contemporain, un musée de l'Énergie, une résidence d'artistes, une bibliothèque, des salles de concert et une partie de l'université Bilgi dont le campus se fond dans les espaces verts du complexe. Le credo de Santralistanbul "création-échange-interdisciplinarité le range au nombre croissant des "nouveaux territoires de l'art" 50 ». Construit sur $118000 \mathrm{~m}^{2}$, il se situe tout au fond de la Corne d'Or, à l'emplacement où le bras de mer finit de s'enfoncer dans le territoire de la métropole. Présent dès le départ du projet (2004) l’État turc représenté par le ministère de l'Énergie et des Ressources naturelles a cédé à l'université Bilgi le droit d'exploiter le site pour des événements nationaux et internationaux. La participation des pouvoirs locaux quant à elle consiste en l'entretien par la municipalité du Grand Istanbul des espaces verts du centre, tandis que la municipalité d'Eyüp, sur le territoire de laquelle Santralistanbul est installée, s'engage à entretenir la future «rue des arts» qui devra, à l'avenir, longer le site. Elle a confié cet espace

46 - J. Grouiller, «La reconversion de la centrale électrique Silahtaraga. Analyse d'une opération de reconversion de friche industrielle urbaine au travers de ses références et des acteurs impliqués ", mémoire de maîtrise d'urbanisme et d'aménagement, Paris, université Paris-VIII, 2005, p. 60.

47 - Ibid., p. 62.

48 - Ibid., p. 73

49 - Ibid.

50 - Voir sur le site de La Belle de mai, l'article consacré à Santralistanbul par Yanna Maudet (http://www.lafriche.org/friche/zdyn1/rubrique.php3?id_rubrique=341) en avril 2007. 
du domaine public à la Fondation Bilgi qui devra en assurer la programmation, choisir artistes et actions qui l'animeront ${ }^{51}$.

\section{Conclusion}

À propos des «jeux» que dans la Rome antique les notables évergètes offraient au peuple, Paul Veyne pose la question suivante: "Pourquoi les Romains se sentaient-ils donc tenus de sacrifier leur argent par devoir envers le public, alors que les Français ne sentent rien de tel et n'hésitent pas à frauder le fisc en rejetant la charge fiscale sur leur prochain? Bref, la pression de l'opinion, la honte devant le prochain, n'explique rien : ce ressort ne fonctionne que si l'individu fait vanité de tel devoir à certaines époques et d'autres devoirs en d'autres temps. L'orgueil et le sens moral ont toujours existé, le poids de l'opinion également: mais pourquoi ont-ils eu quelque fois des évergésies pour objet ${ }^{52}$ ?" À cette interrogation Paul Veyne tente de répondre par un ouvrage de près de neuf cents pages. Le présent article n'a pas la prétention de transposer une telle analyse à la période moderne. Nous nous sommes cependant inspiré des questions posées par l'historien et avons interrogé certains des mécanismes qui ont poussé sur le devant de la scène cette figure d'homme d'affaires-collectionneur-donateur depuis les années 1990 à Istanbul. Nous avons tenté de décrire les initiatives de cet acteur et fait apparaître les missions qu'il s'est attribuées : mission d'enrichir l'offre culturelle et artistique pour les élites stambouliotes d'une part, mais aussi mission diplomatique consistant à inscrire Istanbul dans le réseau des métropoles mondiales, à en faire l'emblème d'une Turquie appartenant résolument au bloc européen, occidental. Ce donateur mène des actions qui obéissent aux paradigmes contemporains de l'utilisation de la culture pour la régénération urbaine. Ses choix de localisations territoriales dérivent de ses missions et ont donc pour incidence soit d'apporter - modérément - des services publics et privés à certains quartiers en déshérence, soit de ressusciter la vocation européenne d'autres districts, soit de faire émerger une œuvre architecturale qui frappe les esprits et impose un nouvel emblème de la ville. Si cet article s'est focalisé sur les missions de ce nouvel acteur, il n'a guère développé la nature de ses motivations particulières, privées. À quelles contraintes, à quelles normes et pour quelle place sociale l'homme d'affaires-collectionneur-donateur turc prodigue-t-il sa générosité? La description d'initiatives qui précède permet d'avancer qu'elles font entrer leurs auteurs dans le «club» des collectionneurs, créateurs de musées, amateurs d'art et cela sur une scène non pas nationale mais mondiale. C'est là d'ailleurs un des éléments qui distinguent ces mécènes de ceux du XIX ${ }^{e}$ siècle, dont l'horizon se limitait aux frontières nationales. Aujourd'hui le mécène, soit particulier soit d'entreprise, s'inscrit dans un champ d'action mondial : François Pinault installe ses collections à Venise, la firme japonaise Honda contribue à financer la restauration du musée Camondo à Paris. C'est à ce réseau d'acteurs internationaux qu'appartiennent désormais les collectionneurs-donateurs turcs.

51 - J. Grouiller, op.cit., p. 76.

52 - P. Veyne Du pain..., op.cit., p. 33 
Collectionner, faire donation, est un marqueur social majeur qui s'impose comme contrainte aux notables aspirant au leadership de la bourgeoisie mondialisée. La concurrence des villes se double de la concurrence d'acteurs privés que sont ces "bienfaiteurs" dont le rôle se situe à mi-chemin entre celui de l'évergète qui "fait profiter de sa fortune» en assumant des missions que l'État ne s'approprie pas ou plus et celui de mécène protecteur des arts à la manière des Médicis, des Borgia ou, plus près de notre ère, de Peggy Guggenheim. 